\title{
Front Matter: Volume 7516
}

, "Front Matter: Volume 7516," Proc. SPIE 7516, Photonics and Optoelectronics Meetings (POEM) 2009: Optoelectronic Devices and Integration, 751601 (4 November 2009); doi: 10.1117/12.852323 


\title{
PROCEEDINGS OF SPIE
}

Photonics and Optoelectronics Meetings (POEM) 2009

Optoelectronic Devices

and Integration

\author{
Zishen Zhao \\ Ray Chen \\ Yong Chen \\ Jinzhong $Y u$ \\ Junqiang Sun \\ Editors \\ 8-10 August 2009 \\ Wuhan, China \\ Organized by \\ Wuhan National Laboratory for Optoelectronics (China) \\ Sponsored by \\ Chinese Optical Society • Huazhong University of Science and Technology (China) • China Hubei \\ Provincial Science Technology Department • Administration Committee of Wuhan East Lake High-Tech \\ Development Zone (China) • The State Optoelectronic Information Industry Base of China \\ Supported by \\ Ministry of Education of China $\bullet$ Optical Society of America $\bullet$ Laser Institute of America $\bullet$ Frontiers of \\ Optoelectronics in China • Editorial Office of Optics \& Optoelectronics Technology • Opticsjournal.net \\ OFweek.com • The China Science-Meeting Online • Laser Manufacture News \\ Published by \\ SPIE
}

Volume 7516

Proceedings of SPIE, 0277-786X, v. 7516 
The papers included in this volume were part of the technical conference cited on the cover and title page. Papers were selected and subject to review by the editors and conference program committee. Some conference presentations may not be available for publication. The papers published in these proceedings reflect the work and thoughts of the authors and are published herein as submitted. The publisher is not responsible for the validity of the information or for any outcomes resulting from reliance thereon.

Please use the following format to cite material from this book:

Author(s), "Title of Paper," in Photonics and Optoelectronics Meetings (POEM) 2009: Optoelectronic Devices and Integration, edited by Zishen Zhao, Ray Chen, Yong Chen, Jinzhong Yu, Junqiang Sun, Proceedings of SPIE Vol. 7516 (SPIE, Bellingham, WA, 2009) Article CID Number.

ISSN 0277-786X

ISBN 9780819479051

Published by

SPIE

P.O. Box 10, Bellingham, Washington 98227-0010 USA

Telephone +1 3606763290 (Pacific Time) · Fax +1 3606471445

SPIE.org

Copyright (C) 2009, Society of Photo-Optical Instrumentation Engineers

Copying of material in this book for internal or personal use, or for the internal or personal use of specific clients, beyond the fair use provisions granted by the U.S. Copyright Law is authorized by SPIE subject to payment of copying fees. The Transactional Reporting Service base fee for this volume is $\$ 18.00$ per article (or portion thereof), which should be paid directly to the Copyright Clearance Center (CCC), 222 Rosewood Drive, Danvers, MA 01923. Payment may also be made electronically through CCC Online at copyright.com. Other copying for republication, resale, advertising or promotion, or any form of systematic or multiple reproduction of any material in this book is prohibited except with permission in writing from the publisher. The CCC fee code is 0277-786X/09/ $\$ 18.00$.

Printed in the United States of America.

Publication of record for individual papers is online in the SPIE Digital Library.

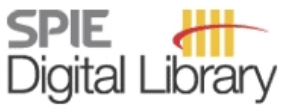

SPIEDigitalLibrary.org

Paper Numbering: Proceedings of SPIE follow an e-First publication model, with papers published first online and then in print and on CD-ROM. Papers are published as they are submitted and meet publication criteria. A unique, consistent, permanent citation identifier (CID) number is assigned to each article at the time of the first publication. Utilization of CIDs allows articles to be fully citable as soon they are published online, and connects the same identifier to all online, print, and electronic versions of the publication. SPIE uses a six-digit CID article numbering system in which:

- The first four digits correspond to the SPIE volume number.

- The last two digits indicate publication order within the volume using a Base 36 numbering system employing both numerals and letters. These two-number sets start with 00, 01, 02, 03, 04, $05,06,07,08,09,0 A, 0 B \ldots 0 Z$, followed by 10-1Z, 20-2Z, etc.

The CID number appears on each page of the manuscript. The complete citation is used on the first page, and an abbreviated version on subsequent pages. Numbers in the index correspond to the last two digits of the six-digit CID number. 


\section{Contents}

vii Symposium Committees

xi Conference Committee

\section{OPTOELECTRONICS DEVICES AND INTEGRATION}

751602 A third-order silicon microring add-drop filter with high extinction ratios [7516-26]

X. Xiao, Q. Huang, Y. Li, Z. Fan, W. Han, Y. YU, J. Yu, Institute of Semiconductors (China)

751603 Birefringence and formed birefringence in photonic crystal line waveguides [7516-41]

W. Zhang, Xi'an Institute of Optics and Precision Mechanics (China) and Graduate School of the Chinese Academy of Sciences (China); J. Liu, Xi'an Institute of Post and Telecommunications (China); W.-P. Huang, McMaster Univ. (Canada); W. Zhao, Xi'an Institute of Optics and Precision Mechanics (China)

751604 Electronic dispersion compensation for high speed long haul transmission with DQPSK modulation [7516-31]

L. Lu, Huazhong Univ. of Science and Technology (China) and Air Force Radar Academy

(China); J. Lei, X. Luo, L. Bing, Huazhong Univ. of Science and Technology (China)

751605 Error rate performance of atmospheric laser communication based on bubble model [7516-25]

K. Xu, J. Wang, Huazhong Univ. of Science and Technology (China); Y. Li, Chongqing Univ. of Technology (China)

751606 Fabrication of silicon photonic devices by utilizing industrial CMOS technology [7516-13] Y. Zhao, H. Zhou, W. Wang, J. Yang, M. Wang, X. Jiang, Zhejiang Univ. (China)

751607 Flat-top passband filter based on parallel-coupled double microring resonators in silicon [7516-33]

Q. Huang, X. Xiao, Y. Li, Z. Li, Y. YU, J. Yu, Institute of Semiconductors (China)

751608 High channel-count phase-only sampled fiber Bragg grating and its application to dispersion compensator and multi-wavelength fiber laser (Invited Paper) [7516-01] H. Li, Shizuoka Univ. (Japan)

751609 High color rendering index WLED based on YAG:Ce phosphor and CdS/ZnS core/shell quantum dots [7516-23]

C. Shen, K. Li, China Jiliang Univ. (China)

$75160 \mathrm{~A}$ High efficiency Silicon-on-Insulator grating coupler between submicron waveguides and fibers [7516-37]

Y. Zhu, Z. Li, W. Han, Z. Fan, Y. Yu, J. Yu, Institute of Semiconductors (China) 
7516 OB Inductively coupled plasma etching of SOI and its applications in submicron optical waveguide devices [7516-40]

Z. Fan, W. Han, F. Yang, X. Xu, Q. Huang, X. Xiao, Y. Zhu, Y. Li, Z. Li, Y. Yu, J. Yu, Institute of Semiconductors (China)

7516 OC Mach-Zehnder electro-optic modulator based on silicon nanophotonic waveguide [7516-10]

X. XU, H. Xu, Institute of Semiconductors (China); Z. Fan, Engineering Research Ctr. for Semiconductor Integrated Technology (China); Y. Yu, J. Yu, Institute of Semiconductors (China)

7516 OD Modeling of reflecting sinusoidal uniform phase volume diffractive gratings [7516-47] Y. Yi, Huazhong Univ. of Science and Technology (China) and Wuhan Univ. of Technology (China); D. Liu, Huazhong Univ. of Science and Technology (China)

$7516 \mathrm{OE}$ Optical properties of amorphous $\mathrm{Ba}_{0.7} \mathrm{Sr}_{0.3} \mathrm{TiO}_{3}$ thin films obtained by metal organic decomposition technique [7516-36]

F. Qiu, Z. Xu, Huazhong Univ. of Science and Technology (China)

7516 OF Optical property of $\mathrm{BaTiO}_{3}$ ferroelectric film at room temperature [7516-44]

Y. Fu, X. Zhang, Z. Xu, Huazhong Univ. of Science and Technology (China)

$75160 \mathrm{O}$ Opto-VLSI-based broadband true-time delay generation for phased array beamforming [7516-43]

B. Juswardy, F. Xiao, K. Alameh, Edith Cowan Univ. (Australia)

$7516 \mathrm{OH} \quad$ Opto-VLSI-based reconfigurable photonic RF filter [7516-39]

F. Xiao, M. Shen, B. Juswardy, K. Alameh, Edith Cowan Univ. (Australia)

$751601 \quad$ Performance optimisation of reconfigurable optical add-drop multiplexers employing Opto-VLSI processors [7516-34]

M. Shen, F. Xiao, K. Alameh, Edith Cowan Univ. (Australia)

7516 0J Periodical polymer grating structure with high aspect ratio [7516-42]

J.-K. Kuo, W.-C. Chang, Southern Taiwan Univ. of Technology (Taiwan, China); K.-F. Yarn, Far East Univ. (Taiwan, China); W.-C. Chuang, National Formosa Univ. (Taiwan, China)

7516 OK Polarization coupling of optical pulse in birefringent nonlinear waveguide [7516-11] W. Wang, J. Zhang, Hubei Univ. (China); Y. Wang, Liteon Singapore Pte Ltd. (Singapore)

$7516 \mathrm{OL} \quad$ Preparation and photoluminescence properties of porous silicon [7516-45]

Z. Chen, Z. Xu, Wuhan National Lab. for Optoelectonics (China) and Huazhong Univ. of Science and Technology (China)

$75160 \mathrm{M}$ Proposal and analysis of a double-tip coupler for efficient coupling fiber to slot and strip waveguides [7516-35]

Q. Huang, W. Han, Z. Fan, F. Yang, Y. Liu, X. Xiao, Y. Zhu, Y. Li, Z. Li, Y. Yu, J. Yu, Institute of Semiconductors (China) 
7516 ON Raman spectroscopy of aged rare earth doped ormosils [7516-46]

V. Ranga, Government College Ajmer (India); H. N. Acharya, Indian Institute of Technology (India); R. K. Khanna, BMIT Jaipur (India); A. Kumar, Chino Scientific Instruments

Manufacturing (India)

751600 Recent advances on chip-to-chip optical interconnect (Invited Paper) [7516-51]

D. Lu, Henkel Electronics (China)

7516 OP Simulation of a 1550-nm InGaAsP-InP transistor laser [7516-19]

W. Shi, Univ. of British Columbia (Canada); Z. Duan, Shenzhen Univ. (China); R. Vafaei, N. Rouger, B. Fariji, L. Chrostowski, Univ. of British Columbia (Canada)

$75160 Q \quad$ Simulation of optically switchable and tunable ultrawideband monocycle generation using semiconductor optical amplifier and optical delay line [7516-48]

Z. Hu, J. Sun, J. Shao, Huazhong Univ. of Science and Technology (China)

$75160 R \quad$ SOI based waveguide devices (Invited Paper) [7516-28]

J. Yu, Q. Huang, X. Xu, X. Xiao, Y. Zhu, Y. Liu, Z. Li, Y. Li, Z. Fan, Y. Yu, Institute of

Semiconductors (China)

7516 OS Spectrum analysis technique for measuring time delay of light in SOI micro-ring slow light device [7516-50]

D. Yang, Central Univ. for Nationalities (China); Y. Li, Z. Fan, Semiconductor Institute (China);

X. Chen, S. Feng, M. LV, Y. Yang, Central Univ. for Nationalities (China)

7516 OT Study on the optical property of the micro Fabry-Perot cavity tunable filter [7516-15]

Q. Meng, Huazhong Univ. of Science and Technology (China), Wuhan National Lab. for Optoelectronics (China), and Guangxi Teachers Education Univ. (China); S. Chen, L. Wu, S. Dong, S. Bao, Huazhong Univ. of Science and Technology (China) and Wuhan National Lab. for Optoelectronics (China)

$75160 \mathrm{U}$ The negative refraction of the 2D triangular lattice of air hole in silicon [7516-14] C. Wu, J. Wu, T. Hong, Y. Li, Z. Wang, Peking Univ. (China)

$75160 \mathrm{~V}$ Thin films' thickness uniformity associated with the method of electron beam evaporation [7516-06]

Z. Xia, Y. Xue, P. Guo, Z. Li, Wuhan Univ. of Technology (China)

7516 OW White light emitting diode based on InGaN chip with core/shell quantum dots [7516-17] C. Shen, China Jiliang Univ. (China); Y. Hong, J. Ma, Changqing Oil Field Co., Ltd (China); J. Ming, HangZhou DaMing Fluorescent Material Co., Ltd (China)

7516 OX Multi-channel all-optical format conversions from RZ signals with different duty-cycle to NRZ signals [7516-16]

Y. Yu, X. Zhang, C. Cheng, D. Huang, Huazhong Univ. of Science and Technology (China)

7516 OY A microwave photonic notch filter based on semiconductor optical amplifier and optical filter [7516-22]

E. Xu, X. Zhang, X. Li, L. Zhou, Y. Zhang, Y. Yu, F. Wang, D. Huang, Huazhong Univ. of Science and Technology (China) 
$75160 Z$ A novel L-band multiwavelength mode-locked semiconductor fibre laser [7516-32]

F. Wang, Huazhong Univ. of Science and Technology (China) and Chongqing Univ. of Technology (China); X. Zhang, E. XU, Y. Zhang, Huazhong Univ. of Science and Technology (China)

751610 Design of self-collimating photonic crystal polarization beam splitter [7516-12] J. Li, F. Li, Suzhou Institute of Nano-Tech and Nano-Bionics (China)

Author Index 


\title{
Symposium Committees
}

\author{
General Conference Chairs \\ Chaohui Ye, Chinese Academy of Sciences (China) and Wuhan \\ National Laboratory for Optoelectronics (China) \\ Ahmed H. Zewail, 1999 Nobel Prize Winner in Chemistry; Physical \\ Biology Center for Ultrafast Science and Technology, California \\ Institute of Technology (United States) \\ Bingkun Zhou, Chinese Academy of Sciences (China) and Tsinghua \\ University (China)
}

International Advisory Committee

Peigen Li, Chair, Huazhong University of Science and Technology

(China)

Victor V. Apollonov, General Physics Institute (Russian Federation)

Hegao Cai, Harbin Institute of Technology (China)

Britton Chance, Pennsylvania University (United States)

Ruiliang Chen, Université Laval (Canada)

Yong Chen, Ecole Normale Superieure (France)

Yi-Bing Cheng, Monash University (Australia)

Connie Chang-Hasnain, University of California, Berkeley

(United States)

Russell D. Dupuis, Georgia Institute of Technology (United States)

Don Giddens, Georgia Institute of Technology (United States)

Michael Grätzel, Ecole Polyłechnique Fédérale de Lausanne

(Switzerland)

Dianyuan Fan, Shanghai Institute of Optics and Fine Mechanics

(China)

Xun Hou, Xi'an Institute of Optics and Precision Mechanics (China)

Desheng Jiang, Wuhan University of Technology (China)

Tingye Li, AT\&T Labs (retired) (United States)

Songhao Liu, South China Normal University (China)

Jurgen Michel, Massachusetts Institute of Technology (United States)

David A.B. Miller, Stanford University (United States)

Liwei Lin, University of California, Berkeley (United States)

Bo Liu, National Data Storage Institute (Singapore) 
Mike O'Mahony, University of Essex (United Kingdom)

Hanben Niu, Shenzhen University (China)

Zihe Rao, Nankai University (China)

Xubang Shen, Chinese Academy of Sciences (China)

Kang L. Wang, University of California, Los Angeles (United States)

Naiyan Wang, Institute of Atomic Energy (China)

Lihong Wang, Washington University in St. Lovis (United States)

Qiming Wang, Institute of Semiconductors, Chinese Academy of Sciences (China)

Ian H. White, University of Cambridge (United Kingdom)

Bernd Wilhelmi, Friedric-Schiller-Universität Jena (Germany)

C. P. Wong, Georgia Institute of Technology (United States)

Ke Wu, Université de Montréal (Canada)

Zhizhan Xu, Shanghai Institute of Optics and Fine Mechanics (China)

X. C. Zhang, Rensselaer Polytechnic Institute (United States)

Zisen Zhao, Fiberhome (China) and Wuhan Research Institute (China)

Bingkun Zhou, Tsinghua University (China)

Jimmy Zhu, Carnegie Mellon University (United States)

Zhongliang Zhu, Chinese Academy of Sciences (China)

Program Committee

Qingming Luo, Chair, Wuhan National Laboratory for Optoelectronics (China)

Hiroshi Amano, Meijo University (Japan)

Chin Hsin Chen, National Chiao Tung University (Taiwan, China)

Yong Chen, École Normale Supérieure Paris, CNRS (France)

Dianyuan Fan, Shanghai Institute of Optics and Fine Mechanics (China)

Fuxi Gan, Shanghai Institute of Optics and Fine Mechanics, Chinese

Academy of Sciences (China)

Michael Grätzel, Ecole Polyłechnique Fédérale de Lausanne

(Switzerland)

Dieter Stefan Jäger, Universität Duisburg-Essen (Germany)

Shuisheng Jian, Chinese Academy of Sciences (China)

Desheng Jiang, Chinese Academy of Engineering (China)

Masud Mansuripur, College of Optical Sciences, The University of

Arizona (United States)

Valery V. Tuchin, Saratov State University (Russian Federation)

Lihong Wang, Washington University in St. Louis (United States)

Horst Weber, Technische Universität Berlin (Germany) 
Hequan Wu, Chinese Academy of Engineering (China)

Changsheng Xie, Wuhan National Laboratory for Optoelectronics (China)

Jianquan Yao, Tianjing University (China) and Wuhan National Laboratory for Optoelectronics (China)

Zisen Zhao, Fiberhome (China) and Wuhan Research Institute (China)

Local Organizing Committee

Lin Lin, Chair, Wuhan National Laboratory for Optoelectronics (China)

Yaming Xia, Chair, Administration Committee of Wuhan East Lake Hi-tech Development Zone (China)

Changqing Chen, Wuhan National Laboratory for Optoelectronics (China)

Huafen Chen, Administration Committee of Wuhan East Lake Hi-tech Development Zone (China)

Ling Fu, Wuhan National Laboratory for Optoelectronics (China)

Dongsheng Jiang, State Key Laboratory of Solid State Lasers (China)

Pengcheng Li, Wuhan National Laboratory for Optoelectronics (China)

Deming Liu, Wuhan National Laboratory for Optoelectronics (China)

Xiangshui Miao, Wuhan National Laboratory for Optoelectronics (China)

Junqiang Sun, Wuhan National Laboratory for Optoelectronics (China)

Qianwen Sun, Administration Committee of Wuhan East Lake Hi-tech Development Zone (China)

Peng Wang, Changchun Institute of Applied Chemistry, Chinese Academy of Sciences (China)

Jinzhong Yu, Institute of Semiconductors, Chinese Academy of Sciences (China)

Xiao Zhu, Wuhan National Laboratory for Optoelectronics (China) 
Downloaded From: https://www.spiedigitallibrary.org/conference-proceedings-of-spie on 25 Apr 2023

Terms of Use: https://www.spiedigitallibrary.org/terms-of-use 


\title{
Conference Committee
}

\author{
Conference Chairs
}

Zishen Zhao, FiberHome Technologies (China) and Wuhan Research Institute (China)

Ray T. Chen, The University of Texas at Austin (United States)

Yong Chen, Ecole Normale Supérieure, Centre National de la Recherche Scientifique (France)

Program Committee

Dexiu Huang, Wuhan National Laboratory for Optoelectronics (China)

Xun Li, McMaster University (Canada)

Sheng Liu, Wuhan National Laboratory for Optoelectronics (China)

Wen Liu, Wuhan National Laboratory for Optoelectronics (China)

Xiaoyi Bao, University of Ottawa (Canada)

Chao Lu, The Hong Kong Polytechnic University (Hong Kong, China)

Mike J. O'Mathony, University of Essex (United Kingdom)

Jesper Moerk, The Technical University of Denmark (Denmark)

Zhanguo Wang, Institute of Semiconductors, Chinese Academy of Sciences (China)

I. H. White, Cambridge University (United Kingdom)

Siyuan Yu., University of Bristol (United Kingdom)

Liming Zhang, Bell Laboratories (United States)

Xinliang Zhang, Wuhan National Laboratory for Optoelectronics (China)

Local Organizing Committee Chairs

Jinzhong Yu, Institute of Semiconductors, Chinese Academy of Sciences (China)

Junqiang Sun, Wuhan National Laboratory for Optoelectronics (China) 
Downloaded From: https://www.spiedigitallibrary.org/conference-proceedings-of-spie on 25 Apr 2023

Terms of Use: https://www.spiedigitallibrary.org/terms-of-use 